\title{
A Top-Oil Thermal Model for Power Trans- formers that Considers Weather Factors
}

\author{
A. Doolgindachbaporn, G. Callender, Member, IEEE, P.L. Lewin, Fellow, IEEE, E. Simonson, and G. \\ Wilson, Member, IEEE
}

\begin{abstract}
The aim of this work is to develop a top-oil thermal model based on the thermal-electrical analogy and heat transfer principles that captures the thermal influence of prevailing winds and solar radiation which can be generally applied to large power transformers. The key improvements of the proposed thermal model are calculating the heat transfer coefficient of the radiator on the air side using the Nusselt number of combined forced and natural convection, and including the solar radiation as an addition heat source. The proposed model is validated with the operational measurements of 3 transformers that are comprised of a 120/240-MVA unit and two 90/180-MVA units. The results are also compared with the predictions based on the IEEE-Annex G model. The proposed model is more accurate over windy and summer periods as expected.
\end{abstract}

Index Terms-Power transformer, transformer thermal model, top-oil temperature, winding temperature indicator.

\section{INTRODUCTION}

$\mathrm{E}$ lectricity demands are increasing because of global decarbonization efforts to reduce emissions that have an impact on climate change [1]. In turn, climate change also impacts on the operation of electrical networks due to increasing ambient temperatures and extreme weather conditions [2]. It is therefore a challenging time for power system owners to operate their assets as efficiently as possible. Accurate estimation of the hotspot temperature of transformers is important for protection, condition monitoring and rating calculations. The thermal-electrical analogy and heat transfer principles are often used to model transformer temperatures [3]. The transformer thermal models usually consist of three main components: ambient air temperature, top-oil and hot-spot temperature [4], [5]. Inside a transformer tank, the heat is produced by the winding and magnetic core. Cooling oil carries the heat generated through a cooler bank where the heat is dissipated to the surrounding environment, cooling the oil. This cold oil is then returned to the tank, completing the thermal circuit. This complex process is described by two governing equations. The first is for top-oil temperature, which is representative of the oil temperature at the top of the transformer tank. The second is for the winding

This work was supported by National Grid Electricity Transmission. A. Doolgindachbaporn, G. Callender and P. L. Lewin are with the Tony Davies High Voltage Laboratory, University of Southampton, Southampton, SO17 1BJ, United Kingdom (e-mail: ad2a15@soton.ac.uk; gmc1f17@soton.ac.uk and pll@ecs.soton.ac.uk)

E. Simonson is with Southampton Dielectric Consultants 1td, Southampton, SO17 1XS, United Kingdom (e-mail edward_sdc@canburytech.net) G. Wilson is with National Grid Electricity Transmission, Warwick, CV34 6DA, United Kingdom (e-mail: gordon.wilson@nationalgrid.com) hot spot temperature, which is used to determine the transformer rating [4]. In this work the impact of solar radiation and prevailing wind on the heat transfer from the oil to surrounding environment is considered by modifying the governing equation for the top oil temperature.

In earlier works it was assumed that the hot-spot temperature rise over top-oil temperature responded immediately to variation in loads [6]. Since fiber optic sensors have been developed for thermal sensing, studies have shown that there is an overshooting response of the hot-spot temperature rise to a step change in load, that means the temperature is greater than the steady-state value during a transient period. [7].

A more accurate transformer thermal model was developed in [8] by taking into account the oil viscosity which is shown to vary significantly over ranges of the operational temperature. The viscosity decreases with increasing temperature and vice versa. The less viscous the fluid is, the more the convective heat transfer is improved. Alternatively, a thermal-hydraulic model has been proposed as a tool for the thermal design [9]. This approach is based on the conservation of heat and mass and pressure equilibrium in closed loops. Several researchers have developed computational fluid dynamics (CFD) models as a tool for the thermal design of transformers [10], [11]. However, this approach requires high computational time and detailed information of transformer design. In this work, a thermal network model is preferred due to its simplicity and the fact that it can be seen as an extension to existing established techniques in the standards [5].

The consideration of environmental factors such as solar radiation and wind is a way to improve the accuracy of transformer models of outdoor units. A previous study on distribution transformers shows that the top-oil temperature could increase by $3.7^{\circ} \mathrm{C}$ on sunny days in summer [12]. There is no significant research carried out regarding the impact of natural winds on the thermal performance of transformers [13]. The impact of natural winds could be significant at a number of sites, in particular transformers installed on offshore platforms for wind farms.

The aim of this work is to develop a transformer thermal model based on the thermal-electrical analogy and heat transfer principles that consider two weather factors: prevailing winds and solar radiation and can be generally applied to any large power transformers using readily accessible data. The key improvements of the proposed thermal model are calculating the heat transfer coefficient of the radiator on the air side using the coefficients of combined forced and natural convection and including the solar radiation as an additional heat source. 


\section{OPERATIONAL MEASUREMENTS}

There were three transformers considered in these analyses. They comprised a 120/240-MVA unit (A) and two 90/180 MVA units (B and C). Their overall specifications are shown in the Appendix in Table V.

All three have the ability to switch between oil-natural-airnatural (ONAN) and oil-forced-air-forced (OFAF) modes. An ONAN model means the heat transfer occurs naturally due to the buoyancy force on both oil and air sides while the heat transfer during forced cooling modes relies on external forces from pumps and fans. For the transformers considered here $\mathrm{A}$ and $\mathrm{B}$ operate in an ONAN state, while transformer C continuously operates in an OFAF state.

The measurement data comprised load profiles, winding temperature indicator (WTI) measurement, wind speed, irradiance and ambient temperature. There are weather stations at the substations of Transformer A, B and C (Fig. 1). The data were recorded every 15 minutes. The analyses have been carried out based on the measurements between July 2019 and May 2020 for Transformer A, B and C. Missing and unreliable data in any load, hot-spot temperature, wind speed, solar radiation or air ambient temperature were deleted from the dataset. As the hotspot temperature rise above the top-oil temperature is calculated by a microprocessor in WTIs in accordance with [5], the top-oil temperature used in the analyses could be back-calculated from the WTI measurements. Direct oil temperature measurements were not available as oil temperature indicators (OTIs) were not fitted to these units The accuracy of the WTI measurement is typically $\pm 2{ }^{\circ} \mathrm{C}$ [14]. The recorded WTI measurement clearly exhibits dependency on wind speed and solar radiation for certain units, as shown Fig. 2 and Fig. 3.

Initially, simple analyses were undertaken to illustrate that weather factors could have significant effects on the transformer temperature. Daily average WTI temperature rise above ambient temperature and load squared are calculated and then plotted against each other as shown in Fig. 2 and Fig. 3 for Transformer A and B, respectively. Fig. 2 shows that the daily average WTI temperature rise is greater on sunny days than cloudy ones, while Fig. 3 shows that the WTI temperature rise is lower on windy days than still days. Windy days are defined here as being those with a daily average wind speed above $4 \mathrm{~m} / \mathrm{s}$, and sunny days are defined here as being those with a daily average solar radiation $0.4 \mathrm{~kW} / \mathrm{m}^{2}$ during daylight hours. Fig. 2 shows that during sunny periods the load on Transformer $\mathrm{A}$ is lower than average. This is as expected because sunny periods will coincide with a lower demand of electricity for heating [15]. Based on the initial analysis, the weather factors do not have significant effects on Transformer $\mathrm{C}$ which is in an OFAF state. This is likely to be because the effect of wind cooling is small compared with forced air from fans and solar radiation is only a small proportion of the total heating for this transformer which is more highly loaded. It is therefore excluded from further investigation. But this analysis does provide motivation for developing transformer thermal models for an ONAN state that can consider these weather factors.

It is noted that imperfect measurement of WTI temperature, ambient temperature, wind speed and solar radiation could all be sources of errors. Nevertheless, the data clearly shows in Fig. 2 and Fig. 3 that the WTI temperature is dependent on weather

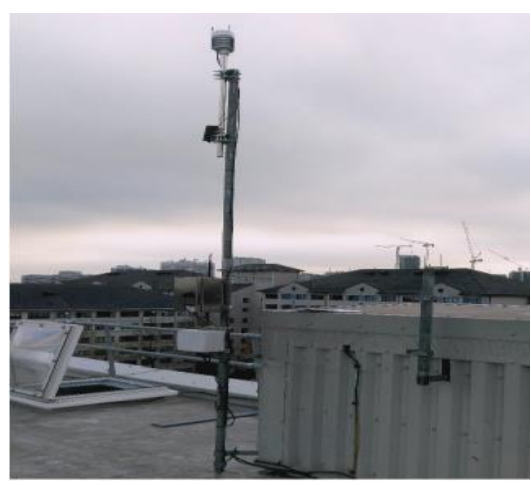

Fig. 1 Weather station at substation of Transformer B.

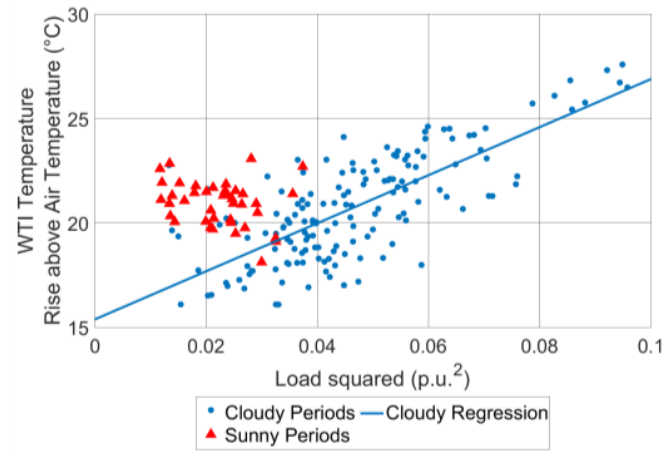

Fig. 2 Daily average WTI temperature rise against load squared for normal and sunny periods for Transformer A.

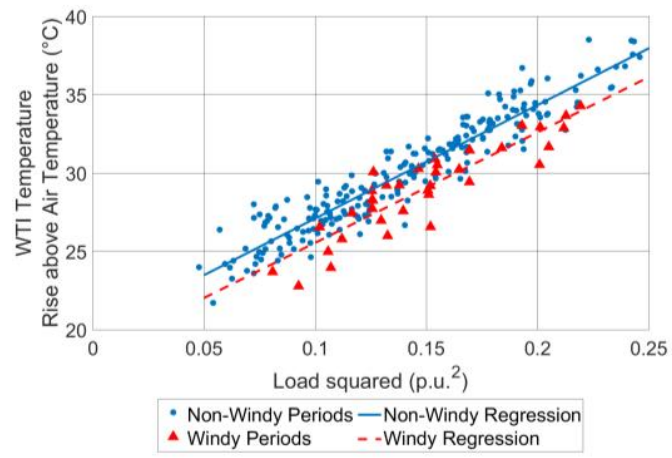

Fig. 3 Daily average WTI temperature rise above ambient temperature against load squared for normal and windy periods for Transformer B.

factors, with the WTI temperature dependent on solar radiation for Transformer A and wind speed for Transformer B. The data provides a clear justification for deriving a transformer thermal model which can consider these weather factors.

\section{TRANSFORMER THERMAL MODEL}

A novel transformer thermal model of the top-oil temperature is proposed by considering two environmental factors: prevailing wind and solar radiation. The thermal model is based on thermal-electrical analogy and heat transfer principle. The proposed model is designed for ONAN units. The novel contribution of the research is the development of a transformer thermal network model that can capture the influence of prevailing wind and solar radiation, which is then tested using field measurements. Direct evidence of prevailing wind impacting transformer temperature has also not been presented in the literature hitherto. 


\section{A. Proposed Top-Oil Model}

The proposed model is based on Swift's model [3] but the top-oil thermal resistances are explicitly split into two regimes: between the oil and the radiator interior and between the radiator exterior and the ambient. For the interior regime, the thermal resistance depends on the oil movement. For the exterior regime, the natural and forced convection due to the air movement and the radiation from the radiator wall are explicitly considered simultaneously. This is especially necessary when the thermal resistance of the air and oil are similar. For example, it is a reasonable assumption to consider only thermal resistance of the air when operating in an ONAN mode because the oil has much lower thermal resistance than the air [3]. However, the situation has changed when fans are working or there is substantial wind as the air's thermal resistance is significantly decreased and is therefore closer to the oil's thermal resistance. The thermal resistance of the radiator steel is neglected as the radiator wall is a good thermal conductor [3].The heat sources are comprised of the magnetic core, winding losses and solar radiation. Fig. 4 illustrates the proposed top-oil thermal circuit. The governing differential equation is as follows:

$$
Q_{\mathrm{Fe}}+Q_{\mathrm{Cu}}=C_{\mathrm{O}} \frac{d \theta_{\mathrm{O}}}{d t}+\frac{\theta_{\mathrm{O}}-\theta_{\mathrm{A}}-R_{\mathrm{MR}, \mathrm{A}} Q_{\mathrm{Solar}}}{R_{\mathrm{N}, \mathrm{O}}+R_{\mathrm{MR}, \mathrm{A}}}
$$

where $Q_{\mathrm{Fe}}$ are the magnetic core losses [W], $Q_{\mathrm{Cu}}$ are the winding losses [W], $Q_{\text {solar }}$ is the total received solar radiation [W], $C_{\mathrm{O}}$ is thermal capacitance $[\mathrm{W} \cdot \mathrm{s} / \mathrm{K}]$ and calculated in accordance with [5], $R_{\mathrm{N}, \mathrm{O}}$ is the thermal resistance between the oil and the interior of the radiator which considers the natural convection of the oil [K/W], $R_{\mathrm{MR}, \mathrm{A}}$ is the thermal resistance between the exterior of the radiator and ambient comprised of the forced and natural convection due to the air $\left(R_{\mathrm{M}, \mathrm{A}}\right)$ and the radiation from the wall $\left(R_{\mathrm{R}}\right), \theta_{\mathrm{O}}$ is the top-oil temperature [ $\left.{ }^{\circ} \mathrm{C}\right]$ and $\theta_{\mathrm{A}}$ is the ambient temperature $\left[{ }^{\circ} \mathrm{C}\right]$. Necessary thermal properties of the air and oil are derived from [16]. It should be noted that all thermal resistances are temperature dependent.

To calculate the effective thermal resistance on the air side and the oil side $\left(R_{\mathrm{MR}, \mathrm{A}}\right.$ and $\left.R_{\mathrm{N}, \mathrm{O}}\right)$, it is necessary to calculate the temperature at the wall of the radiator $\left(\theta_{\mathrm{W}}\right)$. This can be calculated by iteratively solving the following equation, which ensures the continuity of heat flux:

$$
\frac{\theta_{\mathrm{O}}-\theta_{\mathrm{W}}}{R_{\mathrm{N}, \mathrm{O}}}+Q_{\text {Solar }}=\frac{\theta_{\mathrm{W}}-\theta_{\mathrm{A}}}{R_{\mathrm{MR}, \mathrm{A}}}
$$

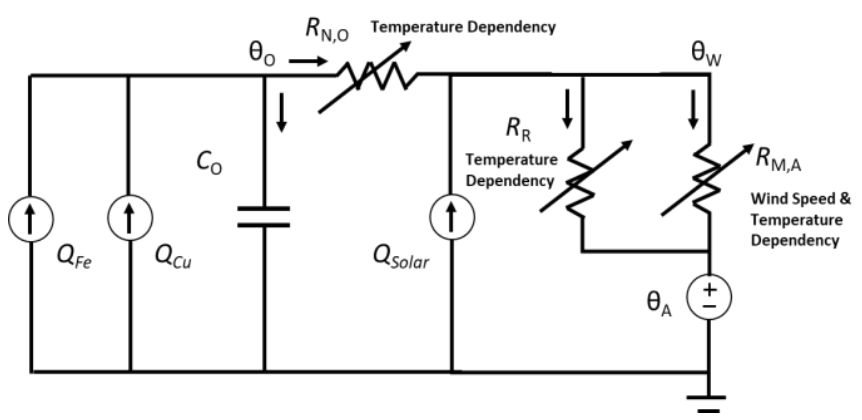

Fig. 4 The proposed top-oil thermal model network that explicitly includes impacts of wind and solar radiation.

\section{B. Oil-to-Wall and Wall-to-Air Convection}

The heat transfer due to convection exists as a result of fluid movement. Within the radiator, the convection occurs due to the oil movement while the convection arises between the exterior of the radiator and ambient due to air movement. The convection can be improved by applying external force, e.g. pumps and fans. The prevailing wind could be considered as external force that improves the heat transfer rate of the radiator.

The thermal resistance due to convection is inversely proportional to heat transfer coefficient and cooling area, it is defined as [17]:

$$
R=\frac{1}{h A_{\mathrm{C}}}=\frac{L}{A_{\mathrm{C}} k \overline{N u}}
$$

where $h$ is a heat transfer coefficient $\left[\mathrm{W} /\left(\mathrm{K} \cdot \mathrm{m}^{2}\right)\right], A_{\mathrm{C}}$ is cooling area due to convection $\left[\mathrm{m}^{2}\right], L$ is characteristic length of heat transfer $[\mathrm{m}], k$ is thermal conductivity of the fluid which will be air or oil $[\mathrm{W} /(\mathrm{m} \cdot \mathrm{K})]$ and $\overline{N u}$ is the Nusselt number.

The Nusselt number $\left(\overline{N u}_{\mathrm{F}}\right)$, Reynold number $\left(R e_{L}\right)$, and Prandtl number $(\mathrm{Pr})$ of forced convection for constant heat flux on a vertical plate with a laminar flow are based on empirical correlations as follows [17]:

$$
\begin{aligned}
\overline{N u}_{\mathrm{F}} & =D_{1} \operatorname{Pr}^{1 / 3} \operatorname{Re}_{L}{ }^{1 / 2} \\
R e_{L} & =\frac{u L_{\mathrm{F}} \rho}{\mu} \\
\operatorname{Pr} & =\frac{\mu}{\alpha \rho}
\end{aligned}
$$

where $D_{1}$ is an empirical constant, $L_{\mathrm{F}}$ is characteristic length for forced convection $[\mathrm{m}], u$ is wind speed $[\mathrm{m} / \mathrm{s}], \mu$ is dynamic viscosity of air $[\mathrm{kg} /(\mathrm{m} \cdot \mathrm{s})], \rho$ is density of air $\left[\mathrm{kg} / \mathrm{m}^{3}\right]$ and $\alpha$ is thermal diffusivity of air $\left[\mathrm{m}^{2} / \mathrm{s}\right]$.

The Nusselt number $\left(\overline{N u}_{\mathrm{N}}\right)$ and Rayleigh number $\left(R a_{L}\right)$ of natural convection on a vertical plate with a laminar flow based empirical correlations are expressed as [17]:

$$
\begin{array}{r}
\overline{N u}_{\mathrm{N}}=D_{2} R a_{L}{ }^{\frac{1}{4}} \\
R a_{L}=\frac{\mathrm{g} \beta c_{p} \rho^{2} \Delta \theta L_{\mathrm{N}}{ }^{3}}{\mu k}
\end{array}
$$

where $D_{2}$ is an empirical constant, $L_{\mathrm{N}}$ is characteristic length for natural convection [m], $\mu$ is dynamic viscosity of the fluid which will be air or oil $[\mathrm{kg} /(\mathrm{m} \cdot \mathrm{s})], c_{p}$ is specific heat of the fluid $[\mathrm{W} \cdot \mathrm{s} /(\mathrm{kg} \cdot \mathrm{K})], \mathrm{g}$ is gravitational constant $\left[\mathrm{m} / \mathrm{s}^{2}\right], \rho$ is density of the fluid $\left[\mathrm{kg} / \mathrm{m}^{3}\right], \Delta \theta$ is the temperature difference over the fluid medium which will be a temperature difference of the oil above radiator wall for the interior of the radiator and a temperature difference of the radiator wall above air the exterior of the radiator $[\mathrm{K}] . \beta$ is thermal expansion coefficient of the fluid $[1 / \mathrm{K}]$. 
The heat transfer coefficient of mixed forced and natural convection of air is expressed as follows [18]:

$$
h_{\mathrm{M}, \mathrm{A}}=\left(h_{\mathrm{F}, \mathrm{A}}^{3.2}+h_{\mathrm{N}, \mathrm{A}}^{3.2}\right)^{\frac{1}{3.2}}
$$

where $h_{\mathrm{F}, \mathrm{A}}$ is the heat transfer coefficient of forced convection of air $\left[\mathrm{W} /\left(\mathrm{K} \cdot \mathrm{m}^{2}\right)\right]$ and $h_{\mathrm{N}, \mathrm{A}}$ is the heat transfer coefficient of natural convection of air $\left[\mathrm{W} /\left(\mathrm{K} \cdot \mathrm{m}^{2}\right)\right] . h_{\mathrm{M}, \mathrm{A}}$ is then used to determine the thermal resistance through (3).

As the radiators of transformers are not perfectly planar the values of empirical constants $\left(D_{1}\right.$ and $\left.D_{2}\right)$ are treated as free parameters. The fitted values are determined using trust-regionreflective algorithms [19]. To avoid the fitted values becoming unrealistic, both constants are restricted to between 0 and 1 . A comparison of the fitted values is made against literature values, [17], which are 0.68 and 0.59 for $D_{1}$ and $D_{2}$ respectively.

The wind direction will influence the extent to which it can penetrate the radiator. The reduction due to the alignment is considered by treating $D_{1}$ as a free parameter. Generally, the wind has a prevailing direction at any given site so the value of $D_{1}$ for any given location, radiator type and orientation should remain roughly constant.

$R_{\mathrm{M}, \mathrm{A}}$ is expressed in terms of a combination of forced and free convective thermal resistance of the air by substituting (9) in (3) as follows:

$$
R_{\mathrm{M}, \mathrm{A}}=\frac{1}{A_{\mathrm{C}} h_{\mathrm{M}, \mathrm{A}}}
$$

where $A_{\mathrm{C}}$ is cooling area $\left[\mathrm{m}^{2}\right]$ and $h_{\mathrm{M}, \mathrm{A}}$ is the heat transfer coefficient of mixed convection of air $\left[\mathrm{W} /\left(\mathrm{K} \cdot \mathrm{m}^{2}\right)\right]$.

$R_{\mathrm{N}, \mathrm{O}}$ is calculated in the same way as $R_{\mathrm{N}, \mathrm{A}}$, replacing the air's thermal properties with the oil's properties. $R_{\mathrm{MR}, \mathrm{A}}$ is calculated as the total resistance of two thermal resistances connected in parallel as follows:

$$
R_{\mathrm{MR}, \mathrm{A}}=\left(\frac{1}{R_{\mathrm{M}, \mathrm{A}}}+\frac{1}{R_{\mathrm{R}}}\right)^{-1}
$$

where $R_{\mathrm{R}}$ is a thermal resistance due to radiative heat transfer of the radiator wall $[\mathrm{K} / \mathrm{W}]$.

\section{Radiative Heat Transfer}

Transformers are not only receiving heat from the sun, but they also transfer heat to the surrounding environment via radiation. The radiative thermal resistance $\left(R_{\mathrm{R}}\right)$ is [20]:

$$
R_{\mathrm{R}}=\frac{1}{\varepsilon \sigma A_{\mathrm{R}}\left[\left(\theta_{\mathrm{W}}\right)^{2}+\left(\theta_{\mathrm{A}}\right)^{2}\right]\left(\theta_{\mathrm{W}}+\theta_{\mathrm{A}}\right)}
$$

where $\varepsilon$ is emissivity, $\sigma$ is the Stefan-Boltzmann constant $\left[\mathrm{W} /\left(\mathrm{m}^{2} \cdot \mathrm{K}^{4}\right)\right], A_{\mathrm{R}}$ is the radiating area $\left[\mathrm{m}^{2}\right], \theta_{\mathrm{W}}$ is the radiator wall temperature $[\mathrm{K}]$ and $\theta_{\mathrm{A}}$ is ambient temperature $[\mathrm{K}]$. As the paint color of the transformers is typically grey, a value of 0.9 for $\varepsilon$ is considered reasonable [16].

\section{Additional Heating Due to Solar Radiation}

As the global solar radiation is only recorded on a horizontal surface, the global solar radiation on vertical surfaces is estimated based on the solar radiation on the horizontal surface. The global solar radiation of a tilted surface is estimated as follows [21]:

$$
\begin{aligned}
q_{\text {global }}=q_{\text {dir }} R_{b}+ & 0.5 q_{\text {indir }}(1+\cos \emptyset) \\
& +0.5 p_{\text {gr }}\left(q_{\text {dir }}+q_{\text {indir }}\right)(1-\cos \emptyset)
\end{aligned}
$$

where $q_{\mathrm{dir}}\left[\mathrm{W} / \mathrm{m}^{2}\right]$ and $q_{\text {indir }}\left[\mathrm{W} / \mathrm{m}^{2}\right]$ are the direct and indirect radiation on a horizontal surface, respectively, $R_{b}$ is the ratio of the direct radiation on the tilted surface to that on a horizontal surface, $p_{g r}$ is albedo factor and $\varnothing$ is tilted angle with respect to the ground [rad]. A value of 0.3 for $p_{g r}$ is typically found for weathered gray concrete [22]. The $R_{b}$ is dependent on the altitude and azimuth angles and the location of the surface and is expressed as follows:

$$
R_{b}=\cos \emptyset+\sin \emptyset \tan (Z N) \cos (A Z-\vartheta)
$$

where $\vartheta$ is the surface azimuth rotation angle [rad], $Z N$ is zenith angle [rad] and $A Z$ is azimuth angle [rad]. The azimuth and zenith angles are dependent on the time of the year and location of the transformer. Detailed calculation for the altitude and azimuth angles can be found [23].

The indirect radiation for the UK could be estimated as follows [24]:

$$
\begin{gathered}
q_{\text {indir }}=q_{\text {global } \mathrm{H}} \bar{k}_{\text {indir }} \\
\bar{k}_{\text {indir }}=0.89 \overline{k_{t}^{2}}-1.185 \bar{k}_{t}+0.95
\end{gathered}
$$

where $\bar{k}_{\text {indir }}$ is the monthly-averaged ratio of the indirect to global radiation, $q_{\text {global H }}$ is the global radiation on a horizontal surface measured by the local weather station, and $\overline{k_{t}}$ is the monthly-averaged clearness index. $\bar{k}_{t}$ used in this work is derived from [21], see Table VI.

The direct radiation on a horizontal surface is expressed as follows:

$$
q_{\text {dir }}=q_{\text {global H }}-q_{\text {indir }}
$$

where $q_{\text {global H }}$ is the global radiation on a horizontal surface measured by the local weather station $\left[\mathrm{W} / \mathrm{m}^{2}\right]$ and $q_{\text {indir }}$ is indirect radiation on a horizontal surface $\left[\mathrm{W} / \mathrm{m}^{2}\right]$.

Solar radiation is accounted for using the same approach suggested in [12], taking into account the fact that for the larger power transformers considered in this work comprise of a tank and a cooler bank. In [12] only smaller power transformers were considered, where solar radiation on a main tank and fins attached to it was considered. For the inner of radiator plates, the surface areas are decreased due to shadow of the adjacent plates. The value of the direct radiation on the remaining areas that are not in the shadows is corrected as follows [12]:

$$
q_{\mathrm{diri}}=\left(1-r_{s}\right) q_{\mathrm{dir}}
$$


where $r_{s}$ is the ratio of the shadow to the total area.

There are seven surfaces that receive the solar radiation in total: two vertical surfaces of the radiator, four vertical surfaces of the transformer tank and the horizontal surface of the transformer tank. This is shown in Fig. 5. The total received solar radiation is:

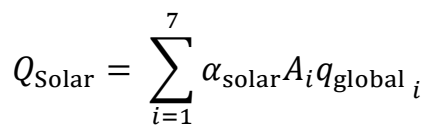

where $\alpha_{\text {solar }}$ is the solar radiation absorption, $A_{i}$ is the receiving area on each surface $\left[\mathrm{m}^{2}\right], q_{\text {global }_{i}}$ is the global radiation on each surface $\left[\mathrm{W} / \mathrm{m}^{2}\right]$. A value of 0.9 for $\alpha_{\text {solar }}$ is considered reasonable for transformers painted with gray color [16]. If the transformer tank is indoor, the tank surface is excluded.

\section{RESULTS AND DISCUSSION}

The proposed model is validated with the operational measurement of Transformers A and B. The data comprised WTI measurement, load, tap position, ambient temperature, wind speed and solar radiation. The analyses have been carried out based on the measurements between July 2019 and May 2020 for Transformer A and B. The total numbers of the data points for Transformer A and B are 25622 and 17796 points with 15minute sampling interval. The first half of the operational measurement is used to adjust the $D_{1}$ and $D_{2}$ by solving a nonlinear least square problem to minimize the error between measurement and simulation, using trust-region-reflective algorithms [19]. The other half of the data is used to evaluate the model accuracy. The results are provided and discussed in this section.

\section{A. Transformer Thermal Parameters}

Table I shows the results of the thermal parameters derived based on the first half of the operational measurement. The values of $D_{1}$ are slightly different from the value derived from the literature [17]. It could imply that the wind may not evenly penetrate through the whole areas of the radiator. The values of $D_{2}$ that are derived from the measurement are slightly higher than the value in the literature [17]. This is probably because the plates of the transformer cooler banks are optimized to increase heat transfer coefficient in comparison with a plain plate. The thermal parameters associated with geometry of transformer are provided in Table II. It was found that the average contribution of the radiative losses from the tank and coolers for a whole year is about $12 \%$ and $2 \%$ to the total losses for Transformer A and $\mathrm{B}$, respectively. The reason that the contribution of Transformer B is relatively smaller is because the main tank is indoors. The contribution of the radiative heat transfer to the total heat transfer varies with transformer designs and operating conditions.

TABLE I

THERMAl PARAMETERS DERIVED FROM THE OPERATIONAL MEASUREMENT

\begin{tabular}{c|c|c}
\hline Transformer & $D_{1}$ & $D_{2}$ \\
\hline $\mathrm{A}$ & 0.69 & 0.62 \\
\hline $\mathrm{B}$ & 0.45 & 0.85 \\
\hline Literature & 0.68 & 0.59 \\
\hline
\end{tabular}

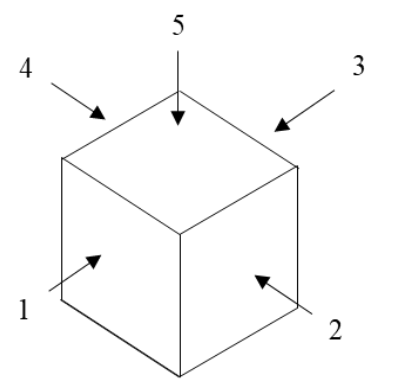

Transformer tank

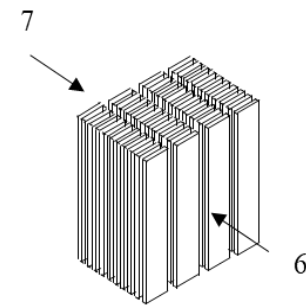

Radiator
Fig. 5 Surfaces of a transformer tank (left) and radiator (right) subjected to solar radiation. This figure is not drawn to scale.

TABLE II

THERMAL PARAMETERS

\begin{tabular}{c|c|c}
\hline Thermal Parameters & Transformer A & Transformer B \\
\hline $\mathrm{L}_{\mathrm{N}}[\mathrm{m}]$ & 2.09 & 3.74 \\
\hline $\mathrm{L}_{\mathrm{F}}[\mathrm{m}]$ & 5.1 & 4.0 \\
\hline Cooling areas $\left[\mathrm{m}^{2}\right]\left[\mathrm{A}_{\mathrm{C}}\right]$ & 1364.5 & 2573.0 \\
\hline $\begin{array}{c}\text { North and south-facing radia- } \\
\left.\text { tor surface areas [m }{ }^{2}\right]\end{array}$ & N/A & N/A \\
\hline $\begin{array}{c}\text { East and west-facing radiator } \\
\text { surface areas }\left[\mathrm{m}^{2}\right]\end{array}$ & 10.66 & 14.96 \\
\hline $\begin{array}{c}\text { North and south-facing Trans- } \\
\text { former surface areas [m²] }\end{array}$ & 24.8 & 11.6 \\
\hline $\begin{array}{c}\text { East and west-facing trans- } \\
\text { former surface areas }\left[\mathrm{m}^{2}\right]\end{array}$ & 15.3 & 28.3 \\
\hline $\begin{array}{c}\text { Top transformer } \\
\text { surface areas }\left[\mathrm{m}^{2}\right]\end{array}$ & 28.6 & 22.6 \\
\hline Radiating areas $\left[\mathrm{m}^{2}\right]\left(\mathrm{A}_{\mathrm{R}}\right)$ & 130.12 & $29.92^{*}$ \\
\hline$C_{\mathrm{O}}[\mathrm{W} \cdot \mathrm{s} / \mathrm{K}]$ & 24012600 & 194174400 \\
\hline$R_{\mathrm{N}, \mathrm{O}}[\mathrm{K} / \mathrm{W}]$ & $1.82 \times 10^{-5}$ & $9.19 \times 10^{-6}$ \\
\hline$R_{\mathrm{MR}, \mathrm{A}}[\mathrm{K} / \mathrm{W}]$ & $1.83 \times 10^{-4}$ & $1.03 \times 10^{-4}$ \\
\hline$R_{\mathrm{M}, \mathrm{A}}[\mathrm{K} / \mathrm{W}]$ & $2.25 \times 10^{-4}$ & $1.06 \times 10^{-4}$ \\
\hline$R_{\mathrm{R}}[\mathrm{K} / \mathrm{W}]$ & $9.84 \times 10^{-4}$ & $4.4 \times 10^{-3}$ \\
\hline
\end{tabular}

*For Transformer B, radiating areas are accounted for radiator surface areas only because the tank is indoors. $R_{\mathrm{N}, \mathrm{O}}, R_{\mathrm{MR}, \mathrm{A}}, R_{\mathrm{M}, \mathrm{A}}$ and $R_{\mathrm{R}}$ are determined at $\theta_{\mathrm{A}}$ of $40^{\circ} \mathrm{C}, 1$ p.u. ONAN rated and no wind and solar radiation.

\section{B. Comparisons between Measurement and Prediction}

The other half of the operational thermal measurements of the two transformers is compared with the predictions made by the proposed model as well as the Annex G in the IEEE guide [5], referred to as the IEEE-Annex $G$ model hereafter. To improve the accuracy of the IEEE-Annex G model the top oil temperature rise at rated load, a key model input, was adjusted to reduce the error between simulated and measured data instead of using the original value derived from the heat run test. This was based on previous investigations by the authors [25]. It should be noted that the set of equations of the IEEE-Annex $G$ model are not modified but only the top-oil temperature rise at rated load is tuned to fit the operational measurement.

Comparisons of the accuracy of the predictions between the IEEE-Annex $G$ and the proposed models on sunny periods for Transformer A that dependency on solar radiation is identified 
are provided in Table III. The results on windy periods for Transformer B that dependency on wind speed is identified are provided in Table IV. In general, the accuracy of the proposed model is not significantly different from the traditional model. However, the improvement of the prediction made by the proposed model is significant when the transformers are subjected to substantial prevailing wind or solar radiation for extend periods of time. The predictions made by the proposed model without considering solar radiation and wind speed intentionally are also included in the results to highlight the improvement due to the consideration of the weather factors.

The root-mean-square errors (RMSEs) between the measurements and predictions based on the IEEE-Annex $G$ and the proposed model over sunny and windy periods are used to evaluate the accuracy. Windy periods are defined here as being those with 6-hour average wind speed above $6 \mathrm{~m} / \mathrm{s}$ and sunny periods are defined here as being those with 6-hour average solar radiation above $0.4 \mathrm{~kW} / \mathrm{m}^{2}$. The transformers were subjected with various load and ambient temperature.

Fig. 6 shows the RMSE against the 6-hour average total receiving solar radiation for Transformer $\mathrm{A}$. There is a significant correlation between the RMSE made by the IEEE-Annex G model and the solar radiation for Transformer A while there is not dependency of the RMSE made by the proposed model on solar radiation. The RMSE of the proposed model is around $3.0^{\circ} \mathrm{C}$ at the solar radiation of $55 \mathrm{~kW}$ while the RMSE of the IEEE-Annex $\mathrm{G}$ model is about $7.5^{\circ} \mathrm{C}$.

The RMSEs made by the IEEE-Annex $\mathrm{G}$ and proposed models at various 6-hour average wind speeds of Transformer B are shown in Fig. 7. For Transformer B, it appears that the errors between the measurement and prediction based on the IEEEAnnex G model increase with increasing wind speeds while the errors for the proposed model do not vary with the wind speeds.

TABLE III

RMSE OF THERMAL MODEL FOR TRANSFORMER A

\begin{tabular}{c|c|c}
\hline Model & All periods & Sunny periods \\
\hline IEEE-Annex G $\left({ }^{\circ} \mathrm{C}\right)$ & 2.96 & 5.92 \\
\hline Proposed Model $\left({ }^{\circ} \mathrm{C}\right)$ & 2.01 & 2.21 \\
\hline Improvement $(\%)$ & 32.1 & 62.7 \\
\hline Proposed Model $(\mathrm{NW})\left({ }^{\circ} \mathrm{C}\right)$ & 2.78 & 4.06 \\
\hline
\end{tabular}

Sunny periods are defined here as being those with 6-hour average solar radiation above $0.4 \mathrm{~kW} / \mathrm{m}^{2}$ and no weather (NW) means weather factor ignored intentionally.

TABLE IV

RMSE OF THERMAL MODEL FOR TRANSFORMER B

\begin{tabular}{c|c|c}
\hline Model & All periods & Windy periods \\
\hline IEEE-Annex G $\left({ }^{\circ} \mathrm{C}\right)$ & 1.96 & 4.53 \\
\hline Proposed Model $\left({ }^{\circ} \mathrm{C}\right)$ & 1.77 & 1.99 \\
\hline Improvement $(\%)$ & 9.5 & 56.1 \\
\hline Proposed Model $(\mathrm{NW})\left({ }^{\circ} \mathrm{C}\right)$ & 2.62 & 5.70 \\
\hline
\end{tabular}

Windy periods are defined here as being those with 6-hour average wind speed above $6 \mathrm{~m} / \mathrm{s}$ and no weather (NW) means weather factors ignored intentionally.

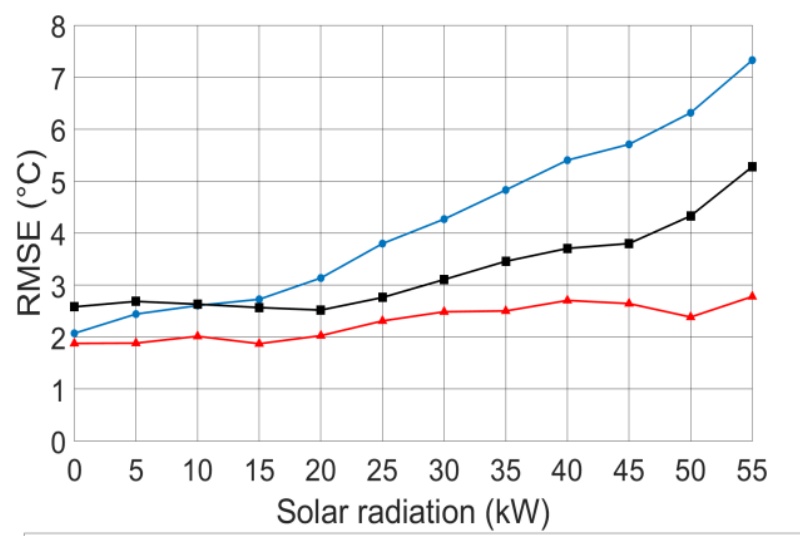

--IEEE-Annex G $\rightarrow$-Proposed Model $\rightarrow$-Proposed Model (NW)

Fig. 6 Statistical errors of the IEEE-Annex $\mathrm{G}$ and proposed models against the total receiving solar radiation for Transformer A. No weather (NW) means weather factors ignored intentionally.

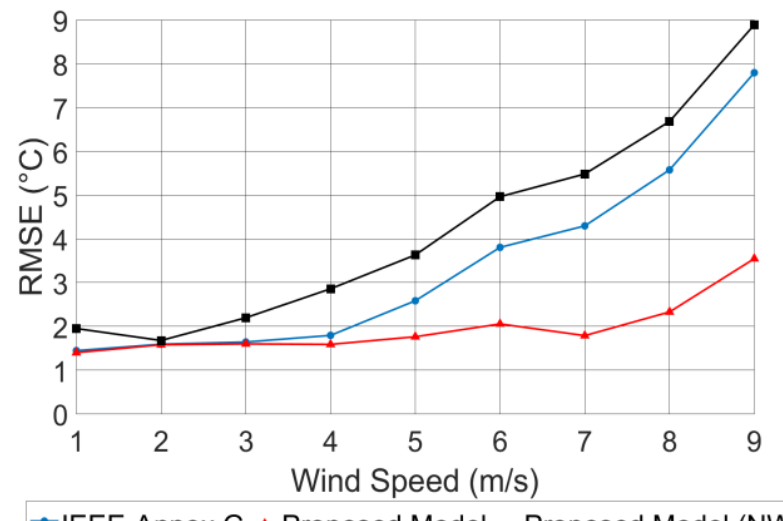

$\rightarrow$-IEEE-Annex G --Proposed Model --Proposed Model (NW)

Fig. 7 Statistical errors of the IEEE-Annex $\mathrm{G}$ and proposed models against wind speed for Transformer B. No weather (NW) means weather factors ignored intentionally.

Examples of WTI measurement and prediction made by the IEEE-Annex G and proposed models for Transformer A on a sunny day and Transformer B on a windy day are shown in Fig. 8 and Fig. 9. The prediction made by the proposed model is typically in closer agreement with the measurement compared with the prediction made by the traditional model. The RMSE of the traditional model is about $8^{\circ} \mathrm{C}$ at the wind speed of $9 \mathrm{~m} / \mathrm{s}$ while the accuracy of the proposed model is higher at the RMSE of $3^{\circ} \mathrm{C}$.

Fig. 10 and Fig. 11 show error duration curves of absolute errors between the measurement and predictions based on the IEEE-Annex $\mathrm{G}$ and proposed models over sunny and windy periods for Transformer A and B, respectively. The accuracy of the prediction made by the proposed model over sunny periods is increased by $4^{\circ} \mathrm{C}$. It appears that the prediction based on the IEEE-Annex $\mathrm{G}$ model is less accurate over windy periods for Transformer B. The overall accuracy of the proposed model over windy periods is improved about $3^{\circ} \mathrm{C}$ for Transformer B. 


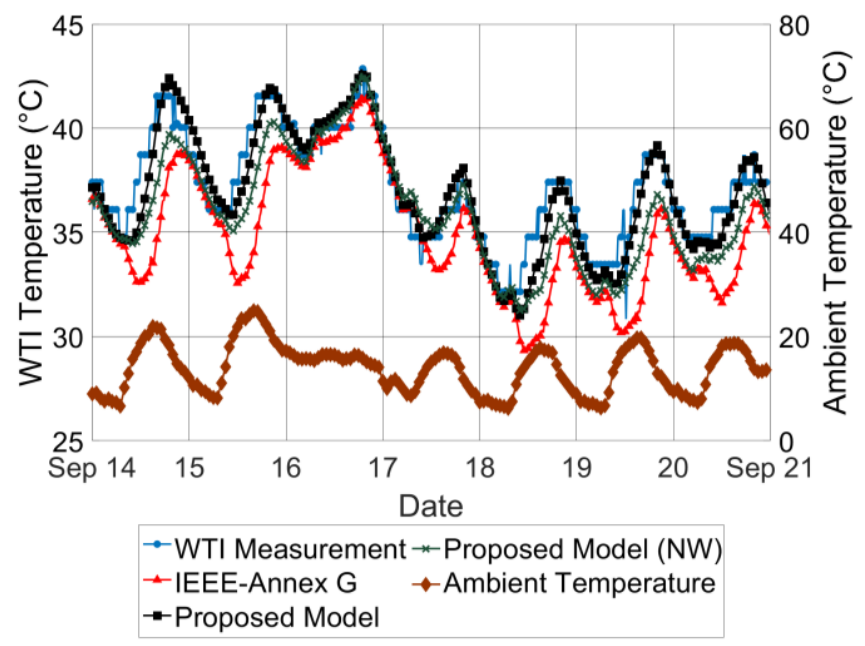

a) WTI measurement and predictions and ambient temperature

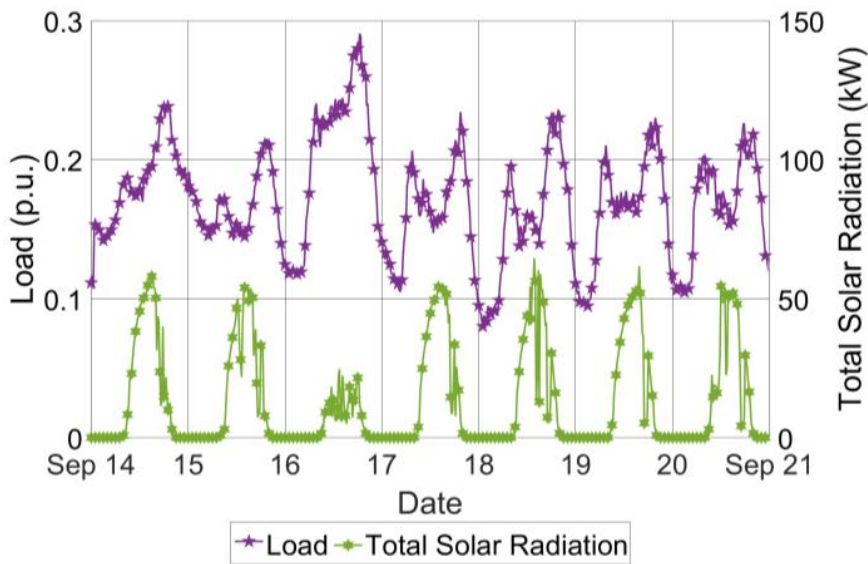

b) Load profile and solar radiation

Fig. 8 Example of WTI measurement and prediction made by the IEEE-Annex $\mathrm{G}$ and proposed models on sunny days for Transformer A.

\section{Effect of Weather Factors on Loss of Transformer Life}

Loss of transformer insulation life is a useful indicator to estimate the remaining life of the solid insulation. Ageing rate of insulation life depends on the transformer hot-spot temperature. According to the IEC guidelines [4], the nominal ageing rate for non-thermally upgraded paper is referenced to the hot-spot temperature of $98^{\circ} \mathrm{C}$. The hot-spot temperature could significantly decrease on windy days. Ignoring the effects of wind could result in overestimating the loss of transformer life. To illustrate the influences of the weather on the ageing rate, the proposed model is used to determine the hot-spot temperature over different loading conditions.

It is assumed that Transformer A continuously carries a load of 1.0 p.u. of the ONAN capacity over 24 hours at daily average ambient temperature of $40^{\circ} \mathrm{C}$. It is worth noting that the loading condition is a hypothetical example for the sake of simplicity. Under typical operation transmission transformers do not operate at this level for extended periods of time. The solar radiation profile is derived from a typical sunny day on summer periods of the historical measurement. The peak solar radiation is about $0.8 \mathrm{~kW} / \mathrm{m}^{2}$ on the horizontal surface. The hot-spot temperature

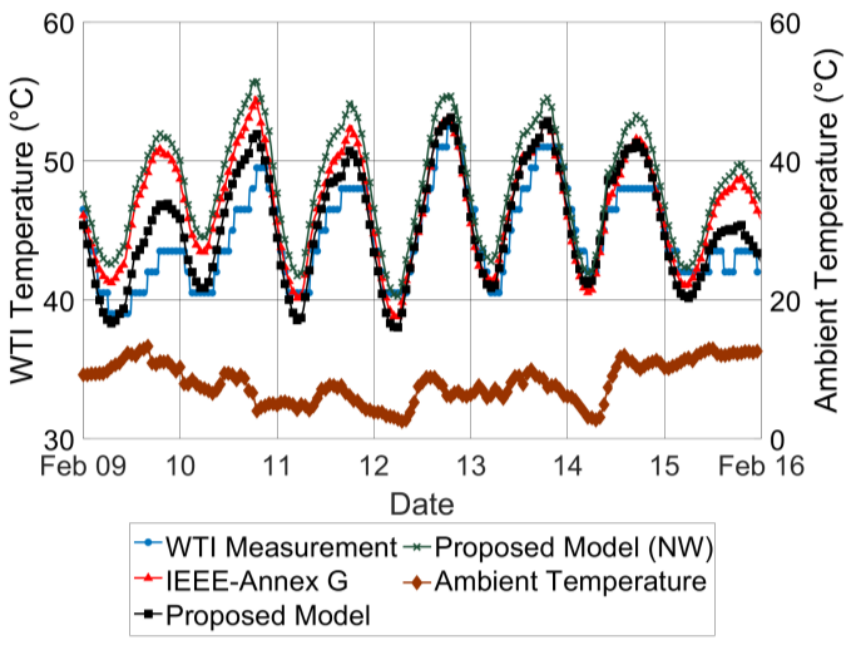

a) WTI measurement and predictions and ambient temperature

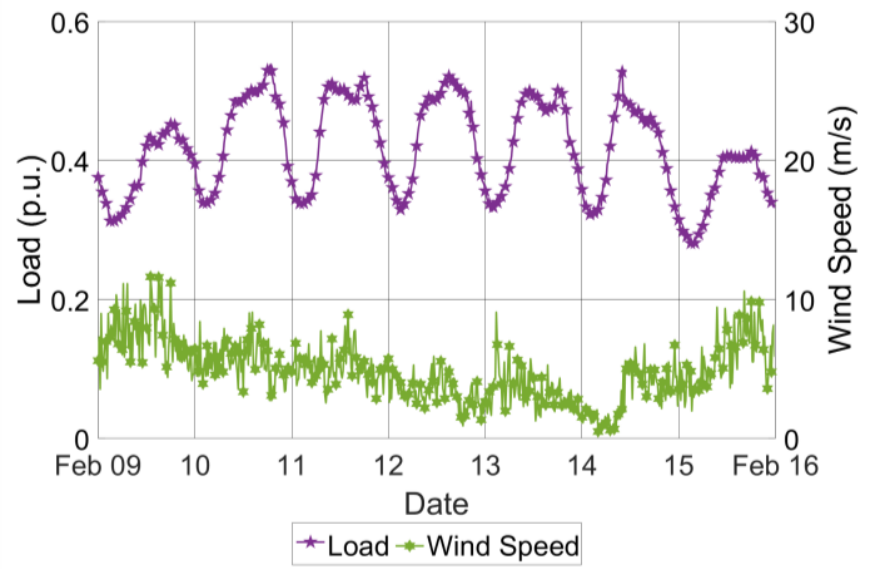

b) Load profile and wind speeds

Fig. 9 Example of WTI measurement and prediction made by the IEEE-Annex $\mathrm{G}$ and proposed models on windy days for Transformer B.

and loss of transformer life are $99^{\circ} \mathrm{C}$ and 27.1 hours without solar radiation and $104.7^{\circ} \mathrm{C}$ and 43 hours with solar radiation respectively. It shows that the solar radiation increases the loss of life by $60 \%$ and the hot-spot temperature by $5.7^{\circ} \mathrm{C}$ for Transformer A.

The hot-spot temperature and loss of life at 1.0 p.u. of the ONAN capacity and various wind speeds for Transformer B are also investigated. The aim is to demonstrate that a substantial prevailing wind could decrease the transformer temperature significantly. It is noted that the actual wind speed usually varies throughout a year and not sustained for extend periods of time. To estimate actual cumulative loss of life, the historical measurement of wind speed will be required. The results are shown in Fig. 12.

The transformer temperature and the loss of life for Transformer B is decreased by approximately 5\% and 30\% at wind speed of $5 \mathrm{~m} / \mathrm{s}$, and $15 \%$ and $60 \%$ at wind speed of $10 \mathrm{~m} / \mathrm{s}$, respectively. The calculation made by the IEEE-Annex $\mathrm{G}$ model may be a relatively conservative estimation for transformers in windy locations, e.g. wind farms and could lead to a decision to replace the transformers earlier than necessary on the loss of life criterion. 


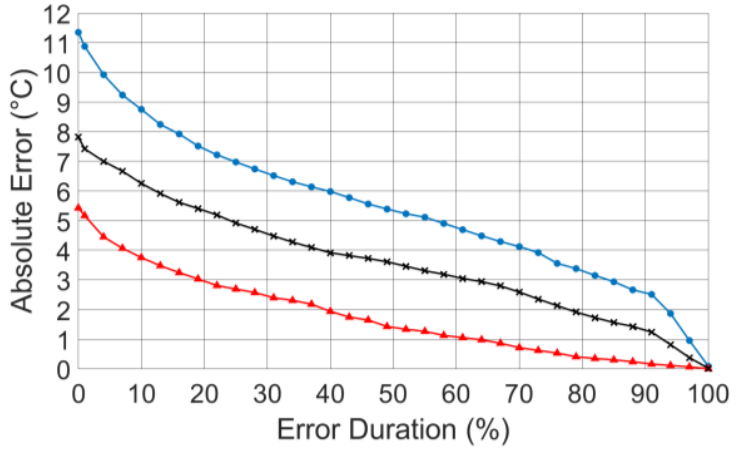

$\rightarrow$-IEEE-Annex G - Proposed Model *-Proposed Model (NW)

Fig. 10 Error duration curve of absolute errors between the measurement and prediction based on the IEEE-Annex $\mathrm{G}$ and proposed models over sunny periods for Transformer A.

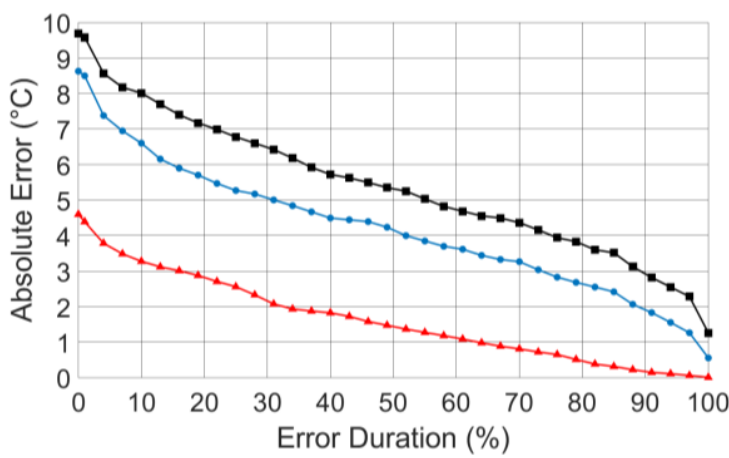

$\rightarrow-$ IEEE-Annex G --Proposed Model --Proposed Model (NW)

Fig. 11 Error duration curve of absolute errors between the measurement and prediction based on the IEEE-Annex $\mathrm{G}$ and proposed models over windy periods for Transformer B.

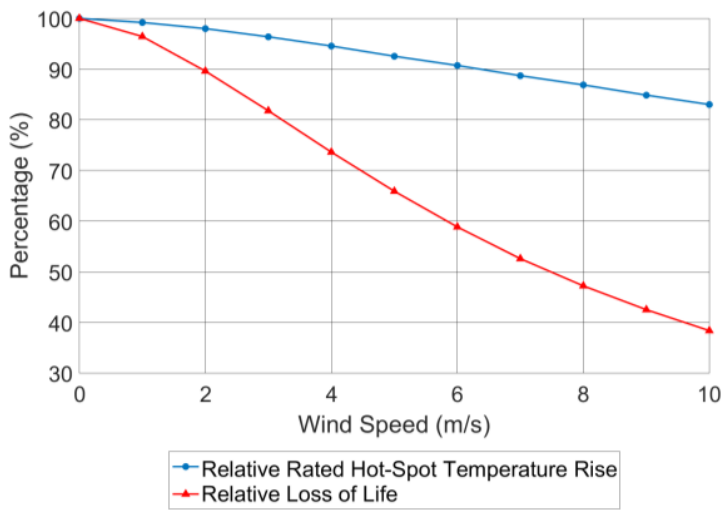

Fig. 12 The calculated hot-spot temperature at rated load and the loss of life with various wind speeds for Transformer B. Note that the average wind speed at this location is $3 \mathrm{~m} / \mathrm{s}$, the wind exceeds $5 \mathrm{~m} / \mathrm{s} 10 \%$ of the time.

\section{CONCLUSION}

A top-oil thermal model that considers the thermal influence of prevailing wind and solar radiation is proposed in this work. The thermal model is based on heat transfer theory and the thermal-electrical analogy. The prevailing wind is considered as an additional forced convection and solar radiation is treated as an additional heat source. The average heat transfer rate can be improved in windy periods resulting in transformer operating at a lower temperature than expected. Solar radiation can cause a measurable increase in temperature particularly for lightly loaded units.
The IEEE-Annex $G$ and proposed models are used to determine the hot-spot temperatures of two different transformers over various conditions. The results show the better agreement between the operational measurement and prediction made by the proposed model over all periods especially windy and sunny periods while the IEEE-Annex $G$ model appears to overestimate the hot-spot temperature during windy periods and underestimate the hot-spot temperature over summer periods. The results show the prevailing wind has less effect when cooling fans are in operation.

In general, environmental effects should be taken into account if attempting to compare the as-installed transformer performance with factory heat run measurements.

\section{APPENDIX}

TABLE V TRANSFORMER PARAMETERS

\begin{tabular}{c|c|c}
\hline \multirow{2}{*}{ Quantity } & \multicolumn{2}{|c}{ Transformer } \\
\cline { 2 - 3 } & A & B \& C \\
\hline HV and LV Voltages, in kV & $400 / 132$ & $275 / 66$ \\
\hline $\begin{array}{c}\text { Rated load for ONAN } \\
\text { and OFAF in MVA }\end{array}$ & $120 / 240$ & $90 / 180$ \\
\hline $\begin{array}{c}\Delta \theta_{\text {O rated for ONAN and }}^{\text {OFAF, in }{ }^{\circ} \mathrm{C}} \\
\text { Load losses at rated load for } \\
\text { ONAN and OFAF, in kW }\end{array}$ & $40.7 / 41.4$ & $41.5 / 39.4$ \\
\hline $\begin{array}{c}\text { No-load losses, in kW } \\
\text { Mass of coil and core, in kg }\end{array}$ & 109000 & $248 / 992$ \\
\hline $\begin{array}{c}\text { Mass of tank and fitting, in } \\
\mathrm{kg}\end{array}$ & 103750 & 128000 \\
\hline \begin{tabular}{c} 
Mass of oil, in kg \\
\hline
\end{tabular} & 108850 & 78250 \\
\hline
\end{tabular}

TABLE VI

MONTHLY-AVERAGED CLEARNESS INDEX FOR THE UK [21]

\begin{tabular}{c|c|c|c|c|c|c}
\hline Month & Jan & Feb & Mar & Apr & May & Jun \\
\hline \multirow{4}{*}{$\bar{k}_{t}$} & 0.24 & 0.29 & 0.34 & 0.35 & 0.39 & 0.43 \\
\cline { 2 - 7 } & Jul & Aug & Sep & Oct & Nov & Dec \\
\cline { 2 - 7 } & 0.4 & 0.39 & 0.39 & 0.35 & 0.31 & 0.25 \\
\hline
\end{tabular}

\section{ACKNOWLEDGMENT}

The authors would like to acknowledge National Grid Electricity Transmission for supporting the project and agreeing to the publication of results. Project Condition and Climatic Environment for Power Transformer (NIA_NGET0213) was made possible through the Network Innovation Allowance.

\section{REFERENCE}

[1] P. J. Baruah, N. Eyre, M. Qadrdan, M. Chaudry, S. Blainey, J. W. Hall, N. Jenkins and M. Tran, "Energy system impacts from heat and transport electrification," Proc. Inst. Civ. Eng. Energy, vol. 167, no. 3, pp. 139151,2014 
[2] W. Thuiller, "Climate change and the ecologist," Nature, vol. 448, pp. 550-552, 2007.

[3] G. Swift, T.S. Molinski and W. Lehn, "A fundamental approach to transformer thermal modeling. I. Theory and equivalent circuit," IEEE Trans. Power Del., vol. 16, no. 2, pp. 171-175, 2001.

[4] Power transformer- Part 7: Loading guide for mineral-oil-immersed power transformers, IEC60076-7, 2018.

[5] IEEE Guide for Loading Mineral-Oil-Immersed Transformers and StepVoltage Regulators, IEEE std C57.91, 2011.

[6] Code of practice, loading guide for oil-immersed transformers, British Standards Institution, 1975.

[7] H. Nordman and M. Lahtinen, "Thermal Overload Test on a 400-MVA Power Transformer With a Special 2.5-p.u. Short Time Loading Capability," IEEE Trans. Power Del., vol. 18, no. 1, pp. 107-112, 2003.

[8] D. Susa, M. Lehtonen and H. Nordman, "Dynamic thermal modelling of power transformers," IEEE Trans. Power Del., vol. 20, no. 1, pp. 197204, 2005.

[9] Z. R. Radakovic and M. S. Sorgic, "Basics of Detailed ThermalHydraulic Model for Thermal Design of Oil Power Transformers," IEEE Trans. Power Del., vol. 25, no. 2, pp. 790-802, 2010.

[10] CIGRE, Transformer Thermal Modelling, Technical Brochure 659, 2016.

[11] X. Zhang, Z. Wang and Q. Liu, "Interpretation of Hot Spot Factor for Transformers in OD Cooling Modes," IEEE Trans. Power Del., vol. 33, no. 3, pp. 1071-1080, 2018.

[12] A. A. Taheri, A. Abdali and A. Rabiee, "A Novel Model for Thermal Behavior Prediction of Oil-Immersed Distribution Transformers With Consideration of Solar Radiation," IEEE Trans. Power Del., vol. 34, no. 4, pp. 1634-1646, 2019.

[13] M. Djamali and S. Tenbohlen, "Hundred years of experience in the dynamic thermal modelling of power transformers," IET Gener. Transm. Distrib., vol. 11, no. 11, pp. 2731-2739, 2017.

[14] "852Plus Transformer Winding Temperature Indicator Single Winding Electronic WTI," Ashridge, [Online]. Available: https://bit.ly/2ZcrLMy. [Accessed 1708 2019].

[15] I. Richardson, M. Thomson, D. Infield, C. Clifford, "Domestic electricity use: A high-resolution energy demand model," Energy Build., vol. 42, no. 10, pp. 1878-1887, 2010.

[16] K. Karsai, D. Kerenyi and L. Kiss, Large Power Transformer, Amsterdam: Elsevier, 1987.

[17] F. P. Incropera, D. P. DeWitt, T. L. Bergman and A. S. Lavine, Fundamentals of Heat and Mass Transfer, New York: Wiley, 2007.

[18] D. L. Siebers, R. G. Schwind and R. J. Moffat, "Experimental mixedconvection heat transfer from a large, vertical surface in a horizontal flow," United States, 1983.

[19] T. Coleman, "An Interior, Trust Region Approach for Nonlinear Minimization Subject to Bounds," SIAM J. Optim, vol. 6, pp. 418-445, 1996.

[20] M. Djamali and S. Tenbohlen, "Malfunction Detection of the Cooling System in Air-Forced Power Transformers Using Online Thermal Monitoring," IEEE Trans. Power Del., vol. 32, no. 2, pp. 1058-1067, 2017.

[21] J.A. Duffie and W.A. Beckman, Solar Engineering of Thermal Processes 2nd edition, New York: Wiley, 1991.

[22] A. C. P. Association, "Albedo: a measure of pavement surface reflectance," Concrete Pavement Research \& Technology 3.05, pp. 1-2, 2002 .

[23] I. Reda and A. Andreas, "Solar position algorithm for solar radiation applications,", Sol. Energy, vol. 76, no. 5, pp. 577-589, 2004.

[24] T. Muneer, S. Etxebarria and E.J. Gago, "Monthly averaged-hourly solar diffuse radiation model for the UK," Build. Serv. Eng. Res. Technol., vol. 35, no. 6, pp. 573-584, 2014.

[25] A. Doolgindachbaporn, G. Callender, J. Pilgrim, P. Lewin and G. Wilson, "The Use of Thermal and Load Data to Identify Large Autotransformers that Have Aged and Degraded Electrical Insulation," 2020 IEEE Electr. Insul. Conf. (EIC), Knoxville, TN, USA, 2020, pp. 313-316.

\section{BIOGRAPHIES}

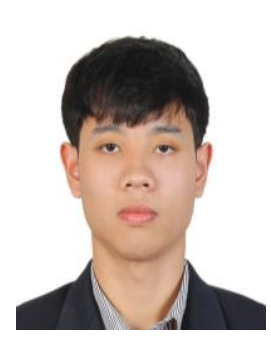

Atip Doolgindachbaporn was born in Bangkok, Thailand in 1992. He received M.Sc. degree in electrical engineering from the University of Southampton, UK in 2017. He is currently a Ph.D. degree student at the University of Southampton. His research interests include power transformer rating and condition monitoring of power transformers.

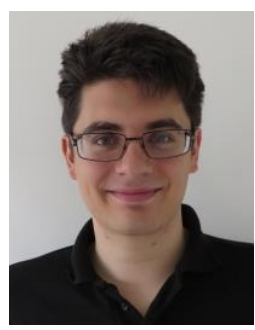

George Callender was born in Basildon, UK in 1991. He received M.Sci (Hons) in Natural Sciences (Maths and Physics) from the University of Durham, UK in 2013. He received a Ph.D. degree in electrical engineering from the University of Southampton, UK in 2018. He is currently a Research Fellow in High Voltage Numerical Modelling at the University of Southampton. His research interests include partial discharge phenomena and the thermal modelling of high voltage plant.

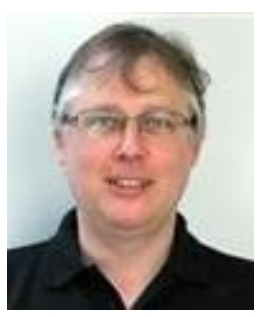

Prof. Paul L. Lewin (M'05-SM'08-F'13) was born in Ilford, Essex in 1964. He received the B.Sc. (Hons) and $\mathrm{Ph} . \mathrm{D}$. degrees in electrical engineering from the University of Southampton, UK in 1986 and 1994, respectively. He joined the academic staff of the University in 1989 and is Head of Electronics and Computer Science, where he is also Director of the Tony Davies High Voltage Laboratory. His research interests are within the generic areas of applied signal processing and control. Within high voltage engineering this includes condition monitoring of $\mathrm{HV}$ cables and plant, surface charge measurement, HV insulation/dielectric materials and applied signal processing. Since 1996 he has received funding and grants in excess of $£ 30 \mathrm{M}$, supervised 50 graduate students to successful completion of their doctoral theses and published over 500 refereed conference and journal papers in these research areas. He is a Chartered Engineer, a Fellow of the IET, and former president of the IEEE Dielectrics and Electrical Insulation Society.

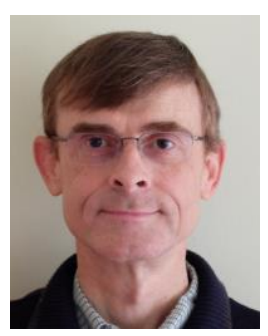

Edward Simonson was born near Gloucester, UK in 1965. He received B.Sc. (Hons) in Physics from the University of Durham, UK, in 1986. He received a D.Phil. Degree in Astronomy from the University of Sussex, UK in 1990. He joined the then new National Grid Company in 1990 to work on detailed thermalhydraulic models of transformer windings and was involved in the measurement and analysis of the first fiber-optic temperature measurements of transformers in the UK. In 2003 he joined Southampton Dielectric Consultants and continued to work on transformer thermal ratings. He has been a member of the maintenance team for the IEC 60076-7 loading guide and a member of the CIGRE working group A2.38 on transformer thermal modelling.

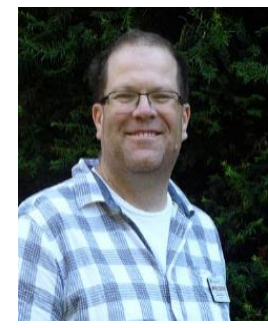

Gordon Wilson (M '08) is a senior innovation engineer at National Grid managing projects on transformers, switchgear and alternatives to SF6. Gordon joined National Grid in 1999 after completing a National Grid-sponsored Ph.D. in chemistry at the University of Surrey. He has primarily worked on transformers and insulating materials over the last 20 years. Throughout his career, Gordon has been involved in research and development and has sponsored $\mathrm{PhD}$ students at Cranfield University, University of Manchester and University of Southampton, where he is a visiting fellow. Gordon is a member of BSi National Committee GEL/10 for electrotechnical fluids, CIGRE Advisory Group D1.01 for liquid and liquid impregnated insulation systems and he has represented the UK in several IEC and CIGRE groups related to oil and transformer ratings. 